Published in final edited form as:

J Alzheimers Dis. 2020 ; 78(2): 643-652. doi:10.3233/JAD-200842.

\title{
Assessing the Reliability of Reported Medical History in Older Adults
}

\author{
Gregory S Day, MD MSc ${ }^{a}$, Allison Long ${ }^{b, c}$, John C Morris, MD ${ }^{c, d}$ \\ aMayo Clinic, Department of Neurology, Jacksonville, Florida, United States of America \\ bHendrix College, Conway, Arkansas, United States of America \\ 'The Charles F. and Joanne Knight Alzheimer Disease Research Center \\ dWashington University School of Medicine, St. Louis, Missouri, United States of America
}

\begin{abstract}
Background: Age-associated increases in medical complexity, frailty and cognitive impairment may compromise reliable reporting of medical history.

Objective: To evaluate the influence of increasing age and cognitive impairment on concordance between reported history of stroke and cerebral infarction, and reported history of diabetes and elevated hemoglobinA1c in community-dwelling older adults.
\end{abstract}

Methods: The association between participant-specific factors and accurate reporting of cerebral infarction or diabetes was evaluated using multivariable logistic regression in 1,401 participants enrolled in longitudinal studies of memory and aging, including 425 participants with dementia (30.3\%). Stroke and diabetes were selected as index variables as gold standard measures of both were obtained in all participants: magnetic resonance neuroimaging for cerebral infarcts and hemoglobinA1c ( $\ .5 \%$ ) for diabetes.

Results: Concordance between reported history of stroke and imaging-confirmed cerebral infarction was low (sensitivity: 17.4\%, 8/46; specificity: 97.9\%, 799/816). Small infarcts were strongly associated with inaccurate reporting (OR=265.8; 95\%CI: 86.2, 819.4), suggesting that occult/silent infarcts contributed to discordant reporting. Reporting accuracy was higher concerning diabetes (sensitivity: 83.5\%, 147/176; specificity: 96.2\%, 1100/1143). A history of hypertension ( $\mathrm{OR}=2.3$; 95\% CI: 1.3, 4.2), higher hemoglobinA1c (OR=1.9; 95\%CI: 1.5, 2.4) and hemoglobinA1c compatible with impaired glucose tolerance $(\mathrm{OR}=3.1 ; 95 \% \mathrm{CI} 1.8,5.3)$ associated with increased odds of discordant reporting. Cognitive impairment and increased age were not independently associated with reliable reporting.

Conclusions: Factors beyond advancing age and cognitive impairment appear to drive discordance in reported medical history in older participants. Objective testing for cerebral infarcts

Address for Correspondence: Gregory S. Day, Mayo Clinic, 4500 San Pablo Rd S, Jacksonville, FL; 32224, day.gregory@ mayo.edu, Phone: 904.953.7228, Fax: 904.953.0707.

Author Contributions:

GS Day participated in study design; acquisition and interpretation of data; statistical analysis; and drafting, revision and finalization of the manuscript.

A Long participated in acquisition and interpretation of data, statistical analysis and drafting of the manuscript.

JC Morris participated in acquisition and interpretation of data, and revision and finalization of the manuscript. 
or diabetes should be performed when relevant to diagnostic or therapeutic decisions in clinical and research settings.

\section{Keywords}

reporting accuracy; medical history; stroke; cerebral infarct; diabetes; cognitive impairment; dementia; Alzheimer disease

\section{Introduction}

A reliable medical history is critical to prioritize investigations, establish accurate clinical diagnoses and select appropriate therapies.[1-3] Conversely, inaccuracies in the medical history contribute to diagnostic errors, inflate the cost of medical care, and increase the risk of morbidity, mortality and medical malpractice claims.[4, 5] Although many sources may inform the medical history, direct patient- and caregiver-reports remain the primary source of information. Patient- and caregiver reported history is especially important when considering conditions defined by interval changes in health status (e.g., dementia[6]), or when determining eligibility and allocation within observational studies and clinical trials. Despite its importance to clinical care and research, few studies have rigorously considered the factors that influence the reliability of direct reporting. Those that have vary in the use of reference standards, yielding conflicting results.[7-10]

Inaccuracies in reporting of medical history may arise from many sources, including errors in reporting due to misunderstandings or misinterpretation of past results, and lack of knowledge concerning an underlying risk factor or health problem. Older adults may be particularly susceptible to inaccurate reporting and associated sequelae owing to ageassociated increases in medical complexity, frailty and cognitive impairment.[11, 12] It is particularly important to identify the factors that influence the reliability of individualreported medical history in this vulnerable population. Recognizing this, we evaluated the concordance between reported history of stroke and diabetes, and detection of cerebral infarction on magnetic resonance (MR) neuroimaging and elevated hemoglobinA1c (HbA1c) in community-dwelling older adults enrolled in longitudinal studies of memory and aging at the Knight Alzheimer Disease Research Center (ADRC; Saint Louis, Missouri). Stroke/cerebral infarction and diabetes were selected as exemplar variables due to their prevalence in the general population, presumed relationship with Alzheimer disease pathophysiology and dementia risk,[13] potential to present or develop insidiously, and the availability of sensitive and specific measures of both disorders (MR neuroimaging for detection of cerebral infarcts[14]; HbA1c for detection of diabetes mellitus;[15]), permitting comparison of reported history with objective reference standards in research participants. We hypothesized that reliability of reporting of medical history would be influenced by key participant-specific variables, including age and cognitive impairment. 


\section{Methods}

\section{Standard protocol approvals, registrations and patient consents}

Community-dwelling older (age >45 years) individuals were recruited from Saint Louis, Missouri and surrounding areas, and enrolled in longitudinal studies of memory and aging at the Knight ADRC. All participants were required to have an observant informant who provided collateral history (a "collateral source"). Participants were asked to participate in core study procedures, including longitudinal clinical assessments, neuropsychological testing, neuroimaging and biofluid measures. Participants (or their delegate) consented to the use of relevant information for research purposes. Research data were compiled and maintained within standalone research records, without reference or consistent crosscorrelation with participant medical records. Data were prospectively collected from April 2005 to April 2019. Study procedures and policies were approved by the Washington University School of Medicine Institutional Review Board.

\section{Clinical assessments}

Participants were evaluated annually by experienced clinicians using semi-structured interviews conducted with the participant and their collateral source, and a detailed neurologic examination of the participant. When appropriate, diagnoses of dementia were rendered by study clinicians, integrating results from the clinical assessment and bedside measures of cognitive function (including the Mini-Mental State Examination; MMSE),[16] referencing established diagnostic criteria.[6, 17] The severity of cognitive impairment was staged using the global Clinical Dementia Rating (CDR®).[18] Demographic variables were obtained at enrollment, including age, race, sex and years of education.

Participants and their collateral sources were queried at each clinical assessment concerning past medical history of "stroke" or diabetes. A reported history of stroke was deemed present in any individual who endorsed a history of stroke at the visit preceding the most recent MR neuroimage. A reported history of diabetes was deemed present in any participant who endorsed a history of type I or type II diabetes mellitus at the visit immediately preceding the most recent $\mathrm{HbA} 1 \mathrm{c}$ measure. Information was obtained from the preceding visit to ensure that reporting was not influenced by the results of research testing. Participants and their informants were also asked concerning past medical history of other variables recognized to associate with cerebral infarction and diabetes, including hypertension, hypercholesterolemia, coronary artery disease (including myocardial infarction, atrial fibrillation, heart valve surgery, cardiac bypass, pacemaker, angioplasty, congestive heart failure or angina), depression and past or present tobacco use (>100 cigarettes). Depressive symptomatology were quantified using the 15 -item Geriatric Depression Scale, and deemed present when the total score was 24 .[19] Medications were reviewed and recorded at each study visit.

\section{Neuroimaging and $\mathrm{HbA1c}$ measures}

Beginning in 2005, participants were asked to undergo structural MR neuroimaging at study enrollment and every three years thereafter. Neuroimaging was performed at Washington University in St. Louis using three different Siemens scanners (Siemens Medical Solutions 
USA, Inc.): Vision 1.5T, TIM Trio 3T, and Biograph mMR PET-MR 3T. Neuroimages were independently reviewed for the presence or absence of ischemic hemorrhagic infarction by board-certified neuroradiologists who were blinded to the participants' medical histories and cognitive status. Cerebral infarcts were identified in accordance with established criteria,[20] and graded as "large" ( $>9 \mathrm{~mm}^{3}$ ) or "small" ( $₫ \mathrm{~mm}^{3}$ ). Susceptibility-weighted MR images were also reviewed and microhemorrhages noted when present. Microhemmorhages were not coded as infarcts, despite their known association with small vessel cerebrovascular disease and cerebral amyloid angiopathy. When more than one MRI was available for a given participant, results from the most recent MRI were used together with data from the proximate clinical assessment.

Beginning in 2006, HbA1c was measured in blood drawn from non-fasted participants immediately following their clinical assessment using the DCA 2000+ Analyzer (Bayer HealthCare LLC, Elkhart, IN). Consistent with the current recommendations of the American Diabetes Association, diabetes was considered present if $\mathrm{HbA1c} \geq 6.5 \%$ (48 $\mathrm{mmol} / \mathrm{mol}$ ); HbA1c 6.0-6.4 was considered at "high risk" for developing diabetes (impaired glucose tolerance).[15] Diabetes was also considered present in participants who reported a history of diabetes and were prescribed medications indicated for the treatment of diabetes, accepting that a lower-than-expected HbA1c may not exclude a history of diabetes in this cohort.

\section{Statistical Analysis}

Demographic and clinical features were summarized using descriptive statistics. Reported history was compared against the reference standards (MR neuroimaging for "stroke", $\mathrm{HbA1c}$ for "diabetes"), and sensitivity, specificity, negative and positive predictive values (NPV, PPV) derived (with 95\% confidence intervals [95\% CI]). True positive and true negatives were defined when the reported history and reference standard were congruent. False positives were defined when the reported history of stroke or diabetes was not corroborated via the reference standard. False negatives were defined when participants denied a history of stroke or diabetes, but cerebral infarction or HbA1c $\geq 6.5 \%$ were detected via the reference standard.

Participants were labelled as accurate (true positive / true negative) or inaccurate (false positive / false negative) reporters. Univariate comparisons were used to explore the relationships between reporting status (concordant / discordant with objective measures) and demographics (age, sex, race, years of education), medical history (hypertension, hypercholesterolemia, coronary artery disease, tobacco use, depression), cognitive status (MMSE; not impaired, $C D R=0$; versus impaired, $C D R>0$ ), marital status and informant relationship. Chi square tests were used to measure differences between categorical variables. Student t-tests (two independent variables, equal variance assumed) were used to measure differences between continuous variables. Variables implicated as potential contributors to reliable reporting ( $\mathrm{p}<0.1$ on univariate analyses) were further evaluated using multivariable logistic regression (forced entry) in models including cognitive impairment and age (prespecified variables of interest), allowing the effect of variables on the accuracy of reporting (dependent variable) to be quantified while adjusting for potential sex-specific 
effects. Model explanatory power was assessed using the c-statistic (area under the receiver operating characteristic curve). Statistical analyses were conducted using SPSS Statistics (IBM Corp., Version 25.0. Armonk, NY). Statistical significance was established at $\mathrm{p}<0.05$, unless otherwise specified.

\section{Data Sharing}

Study data are available to qualified investigators upon approval of a resource request by the Knight ADRC Data Request Committee (https://knightadrc.wustl.edu/research/ resourcerequest.htm).

\section{Results}

Data were available from 1401 unique participants assessed from April 2005 to April 2019. Participants were well-educated (mean 15.7 \pm 2.7 years of education) older adults (mean $73.4 \pm 9.2$ years-of-age). Racial distribution was consistent with the surrounding community: 80.5\% ( $\mathrm{n}=1128)$ of participants were non-Hispanic white; $18.3 \%$ were African American $(n=256)$. The majority of participants were cognitively normal (CDR=0, $n=976: 69.7 \%)$. When present, cognitive impairment was generally very mild (CDR $0.5, n=262: 18.7 \%$ ) or mild (CDR 1, n=138: 9.9\%), with symptoms most commonly attributed to Alzheimer disease (324/425, 76.2\%). Magnetic resonance neuroimaging was performed in 862 participants and HbA1c measured in 1319 participants. Demographic and clinical characteristics are reported in Table 1 for each cohort.

The concordance between reported history of stroke and detection of past ischemic or hemorrhagic infarction on neuroimaging was low, with a sensitivity of $17.4 \%[95 \% \mathrm{CI}$ 6.5-28.3\%] (8/46; eTable 1). A prior history of stroke was reported by $25 / 862$ (2.9\%) participants, yet confirmed on neuroimaging in only 8 of these 25 participants (positive predictive value $=32 \%[95 \% \mathrm{CI} 16.0-52.0 \%])$. The specificity of participant report was $97.9 \%\left(799 / 816\left[95 \%_{\mathrm{CI}} 96.9-98.9 \%\right]\right)$. Infarcts were detected on neuroimaging in 38 participants who did not report a past history of stroke (negative predictive value $=95.5 \%$ [95\% $\mathrm{CI} 94.0-96.8 \%$ ], 799/837). 11/46 infarcts (26\%) were hemorrhagic; all were small ( $₫$ $\mathrm{mm}^{3}$ ). Microhemmorhages were detected on susceptibility-weighted MR neuroimaging in 97 participants (11.2\%). Older age, the presence of cognitive impairment (CDR $\searrow 0.5$ ), greater degree of cognitive impairment (lower MMSE scores), history of hypertension and use of an unrelated collateral source (i.e., close friend or acquaintance) were more frequent in participants with discordant reporting (Table 2).

When these variables were considered together via multivariable logistic regression, the presence of small infarcts emerged as the predominant driver of inaccurate reporting (odds ratio $[\mathrm{OR}]=265.8\left[95 \%_{\mathrm{CI}} 86.2,819.4\right]$; controlling for age and sex). A potential clinically meaningful association between an unrelated collateral source and discordant reporting could not be excluded ( $\mathrm{OR}=2.4$ [95\% ${ }_{\mathrm{CI}}$ 0.99-5.9]; $\mathrm{n}=860$; eTable 2). Cognitive impairment $\left(\mathrm{OR}=1.8\left[95 \%_{\mathrm{CI}} 0.63,5.0\right]\right)$ and increasing age $\left(\mathrm{OR}\right.$ per decade $\left.=1.2\left[95 \%_{\mathrm{CI}} 0.70,2.1\right]\right)$ were not associated with increased odds of discordant reporting. The multivariable model demonstrated a good ability to identify participants in whom reported stroke history and 
neuroimaging findings were most likely to be discordant (c-statistic $=0.87\left[95 \%{ }_{\mathrm{CI}}: 0.81\right.$, 0.93]; $\mathrm{p}<0.001)$.

The sensitivity and specificity of reported history of diabetes was $83.5 \%[95 \% \mathrm{CI}$ 77.8-88.6\%] (147/176) and 96.2\% [95\% CI 95.1-97.3\%] (1100/1143), respectively (eTable 3). A history of diabetes was reported by 190/1319 (14.4\%) participants. Of these, 147 participants had an HbA1c consistent with diabetes ( 26.5 ) or were taking medications for the management of diabetes (positive predictive value $=77.4 \%[95 \% \mathrm{CI} 71.1-83.2 \%]$ ). Serum $\mathrm{HbA1 \textrm {c }}$ was consistent with diabetes in an additional 29 participants who denied a past history of diabetes and who were not taking medications commonly prescribed to treat diabetes (negative predictive value $=97.4 \%[95 \% \mathrm{CI}$ 96.5-98.3\%]). Older age, African American race, a history of hypertension, higher $\mathrm{HgAlc}$, and $\mathrm{HgAl}$ in the range suggesting impaired glucose tolerance (6.0-6.4) were associated with discordant reporting of diabetes (Table 3). When these variables were considered together via multivariable logistic regression, a history of hypertension $\left(\mathrm{OR}=2.3\left[95 \%_{\mathrm{CI}} 1.3,4.2\right]\right)$, higher $\mathrm{HgA} 1 \mathrm{c}(\mathrm{OR}=1.9$ $\left.\left[95 \%_{\mathrm{CI}} 1.5,2.4\right]\right)$ and $\mathrm{HgA} 1 \mathrm{c}$ compatible with impaired glucose tolerance $\left(\mathrm{OR}=3.1\left[95 \%_{\mathrm{CI}}\right.\right.$ $1.8,5.3])$ were independently associated with increased odds of discordant reporting of diabetes $(\mathrm{n}=1318$; eTable 4), when controlling for sex. Cognitive impairment $(\mathrm{OR}=1.0$ $\left.\left[95 \%_{\mathrm{CI}} 0.6,1.7\right]\right)$ and increasing age $\left(\mathrm{OR}\right.$ per decade $\left.=1.1\left[95 \%_{\mathrm{CI}} 0.80,1.5\right]\right)$ were not associated with increased odds of discordant reporting. The multivariable model demonstrated fair ability to identify participants in whom reported history of diabetes and $\mathrm{HbA} 1 \mathrm{c}$ measures were most likely to be discordant $\left(\mathrm{c}\right.$-statistic $=0.79\left[95 \%_{\mathrm{CI}} 0.74,0.84\right]$, $\mathrm{p}<0.001)$.

False negative reporting accounted for the majority of discordance between stroke history and neuroimaging findings $(69 \%, 38 / 55)$, indicating that occult (i.e., clinically silent) infarction accounted for the majority of discordant reports. The opposite was true concerning diabetes: participants were more likely to over-report a history of diabetes ("false positive"), despite an $\mathrm{HbAlc}$ in the normal range $(<6.5 \%)$. The factors associated with false positive and false negative reports were explored through post-hoc analyses (Table 4). Female participants were more likely to over-report (14/17, 82\%) a history of stroke (20/38, $53 \% ; \mathrm{p}=0.04)$. No other differences were noted in participant-specific factors, cognitive function, medical history or other measured variables.

Both neuroimaging and $\mathrm{HbA} 1 \mathrm{c}$ data were available in 780 participants. No relationship was observed between discordant reporting concerning history of stroke and diabetes (interreporter agreement, Cohen's kappa $=0.03$; $\mathrm{p}=0.46$ ); i.e., discordant reporting in one domain did not predict discordance in another.

\section{Discussion}

Discordance between participant reported history of stroke and diabetes and objective measures of cerebral infarcts and chronic elevations in blood glucose were common in community-dwelling older individuals enrolled in longitudinal studies of memory and aging at our center. More than two-thirds of participants who endorsed a prior history of stroke did not have cerebral infarcts on neuroimaging, while $>80 \%$ of participants with imaging- 
confirmed infarcts did not endorse a history of stroke. The presence of small infarcts on neuroimaging was strongly associated with discordant reporting, with abundant "false negative" reports, implying that the majority of cerebral infarcts were undiagnosed, unrecognized or occult/clinically silent. Participants were more reliable when reporting a history of diabetes. Nonetheless, HbA1c was not consistent with diabetes in almost one in four participants who endorsed a history of diabetes, and $16.5 \%$ of participants were unaware that they had diabetes. HbA1c levels consistent with impaired glucose tolerance (6.0-6.4\%) were independently associated with inaccurate reporting, suggesting that participants may have misinterpreted their diabetic status, contributing to false positive reports. A history of hypertension was also associated with greater odds of inaccurate reporting of diabetes history. This may reflect heightened awareness or concern regarding diabetes in participants with other "vascular risk factors" who may be more likely to receive routine blood glucose screening, and counseling concerning the need to manage impaired glucose tolerance and prevent diabetes.[21] This possibility emphasizes the potential for confusion and misinterpretation of information provided by care providers, and the need for increased counseling concerning the implications of "high risk" or prodromal disease states (e.g., impaired glucose tolerance, which may be presented as "early" or "pre-diabetes") and the differences between these transitional states and diagnoses associated with adverse outcomes (e.g., diabetes).

Cognitive impairment and increasing years of age were not associated with reporting accuracy. These findings differ from reports in elderly persons living in northern Manhattan, in whom older age and impaired memory/cognitive skills associated with greater odds of inaccurate self-reporting of stroke.[8] These differences may reflect the generally low-level of cognitive impairment in our participants, recognizing that the majority of participants were very mild or mildly affected (CDR $0.5 / 1.0)$. Additionally, the incorporation of a reliable collateral source in the medical interview may have blunted the influence of cognitive impairment on reporting accuracy in our study. In support of this suggestion, a clinically meaningful association between the participant-collateral source relationship and odds of discordant reporting could not be excluded ( $\mathrm{OR}=2.4$ [95\% ${ }_{\mathrm{CI}}$ : 0.9-5.9]). Inclusion of a reliable collateral source in the medical interview may facilitate engagement and comprehension of shared information,[22, 23] benefits which may be most apparent when assessing cognitive function in individuals with early-stage dementia,[24-26] or when evaluating sicker individuals.[23]

Reporting accuracy was higher for diabetes than "stroke", with fewer false negative reports. This difference may reflect routine screening for diabetes in individuals $>45$ years of age (consistent with recommendations from the American Diabetes Association[15]), facilitating the detection of diabetes in asymptomatic individuals. The chronic nature of diabetes may also have contributed to accuracy, noting that the concordance between self-report and objective measures of disease are generally higher in well-defined conditions that require frequent monitoring (e.g., daily serum glucose checks) and regular use of medications (oral or injection).[27] Conversely, stroke and cerebral infarction are the exemplar acute disease states that may present with symptoms and signs that are easily overlooked or misinterpreted by patients and providers,[12, 28] or with no symptoms at all (silent infarction).

Asymptomatic presentations may be even more common when infarct volume is small, 
contributing to false negative reporting in this study and others, $[29,30]$ and emphasizing the potential for cerebrovascular disease to insidiously progress in older individuals. Selected factors under conscious and unconscious control that may contribute to errors in reporting of medical history are summarized in Table 5, along with strategies that may be leveraged to mitigate discordant reporting of medical history in clinical and research settings.

Beyond informing the factors that influence concordance between historical reports and objective measures of disease, the findings from this study have direct implications for clinical care and research. As outlined in North American screening recommendations,[21] the early detection of diabetes may provide an opportunity to intervene before symptoms or debilitating multi-organ consequences of diabetes manifest. In the same way, the detection of occult infarcts, including small incidental infarcts, should trigger the clinician to screen for and treat other vascular risk factors, with the goal of preventing future strokes and improving outcomes.[34] Accurate recognition of cerebral infarcts and diabetes may be particularly important when assessing individuals with cognitive decline, recognizing the relationship between cerebral infarcts and vascular cognitive impairment, $[35,36]$ and the potential contributions of vascular risk factors and cerebrovascular disease to the age-atsymptomatic onset, phenotype and rates of progression of common age-related neurodegenerative diseases, including Alzheimer disease.[13, 37-39] In this context, our findings highlight the need for caution before acting on historical reports. Stated simply, the presence or absence of cerebral infarcts or diabetes should be objectively confirmed when the findings will be used to direct clinical care, inform diagnostic classification or influence study inclusion/exclusion.

This nested cohort study leveraged data from a robust number of participants enrolled in studies of memory and aging at a single center, with racial breakdown representative of the local population. Prospective collection of information from diverse cohorts and the ability to reference "gold standard" measures for cerebral infarction and persistently elevated blood glucose are notable strengths. However, our results are subject to limitations. Analyses of reporting reliability were limited to diabetes and stroke. Thus, it is unclear whether our findings can be generalized to other diseases (e.g., myocardial infarction) or aspects of the medical history (e.g., medication use). In particular, accurate reporting of diagnoses or habits associated with perceived stigma (e.g., mental illness, substance use) may be influenced by other factors that were not measured in this cohort, warranting further study. Our participant population was relatively well-educated with a lower prevalence of diabetes and symptomatic stroke than is reported in the United States and other community-based studies.[8, 40, 41] Additionally, enrolled participants were willing to participate in annual clinical and neuropsychological assessments, with frequent biofluid sampling and neuroimaging. Higher levels of engagement in research are likely to associate with higher degrees of health literacy and improved access to care. Reporting accuracy may be lower in less-engaged/motivated individuals, and in those from disadvantaged populations, including communities with less access to recommended screening, lower health literacy and more prevalent medical comorbidities. As a result, our findings likely underestimated the potential for discordance between participant-reported history of stroke and diabetes and objective measures in the general population. 


\section{Conclusions}

Discordance between participant-reported history of stroke and diabetes and objective measures were common in older community-dwelling participants enrolled in longitudinal studies of memory and aging at our center. Factors beyond advancing age and cognitive impairment appear to drive discordance in reported medical history. These findings emphasize the need to objectively confirm key elements of history when relevant to diagnostic or therapeutic decision-making in clinical and research settings.

\section{Supplementary Material}

Refer to Web version on PubMed Central for supplementary material.

\section{Acknowledgements}

This study was supported by grants from the National Institutes of Health (K23AG064029, P50AG005681; P01AG003991; P01AG026276). The Authors thank the Knight ADRC Imaging Core, led by Tammie L. S Benzinger, MD, PhD (Department of Radiology, Washington University School of Medicine in St. Louis), for facilitating review of neuroimaging and reporting of results in study participants.

Author Disclosures:

GS Day is supported by a career development grant from National Institutes of Health/National Institute on Aging (K23AG064029). He serves as a topic editor on dementia for DynaMed Plus (EBSCO Industries, Inc), is the clinical director for the Anti-NMDA Receptor Encephalitis Foundation (uncompensated), has provided record review and expert medical testimony on legal cases pertaining to management of Wernicke encephalopathy, and holds stocks $(>\$ 10,000)$ in ANI Pharmaceuticals (a generic pharmaceutical company).

A Long reports no disclosures.

JC Morris is funded by National Institutes of Health grants \# P50AG005681; P01AG003991; P01AG026276 and UF1AG032438. Neither Dr. Morris nor his family owns stock or has equity interest (outside of mutual funds or other externally directed accounts) in any pharmaceutical or biotechnology company.

\section{References}

[1]. Peterson MC, Holbrook JH, Von Hales D, Smith NL, Staker LV (1992) Contributions of the history, physical examination, and laboratory investigation in making medical diagnoses. West $\mathrm{J}$ Med 156, 163-165. [PubMed: 1536065]

[2]. Roshan M, Rao AP (2000) A study on relative contributions of the history, physical examination and investigations in making medical diagnosis. J Assoc Physicians India 48, 771-775. [PubMed: 11273467]

[3]. Kassirer JP (2014) Imperatives, expediency, and the new diagnosis. Diagnosis (Berl) 1, 11-12. [PubMed: 29539968]

[4]. Hautz WE, Kammer JE, Hautz SC, Sauter TC, Zwaan L, Exadaktylos AK, Birrenbach T, Maier V, Muller M, Schauber SK (2019) Diagnostic error increases mortality and length of hospital stay in patients presenting through the emergency room. Scand J Trauma Resusc Emerg Med 27, 54. [PubMed: 31068188]

[5]. Graber ML (2013) The incidence of diagnostic error in medicine. BMJ Qual Saf 22 Suppl 2, ii21ii27.

[6]. McKhann GM, Knopman DS, Chertkow H, Hyman BT, Jack CR Jr., Kawas CH, Klunk WE, Koroshetz WJ, Manly JJ, Mayeux R, Mohs RC, Morris JC, Rossor MN, Scheltens P, Carrillo MC, Thies B, Weintraub S, Phelps CH (2011) The diagnosis of dementia due to Alzheimer's disease: recomamendations from the National Institute on Aging-Alzheimer's Association workgroups on diagnostic guidelines for Alzheimer's disease. Alzheimers Dement 7, 263-269. [PubMed: 21514250] 
[7]. Gupta V, Gu K, Chen Z, Lu W, Shu XO, Zheng Y (2011) Concordance of self-reported and medical chart information on cancer diagnosis and treatment. BMC Med Res Methodol 11, 72. [PubMed: 21592352]

[8]. Reitz C, Schupf N, Luchsinger JA, Brickman AM, Manly JJ, Andrews H, Tang MX, DeCarli C, Brown TR, Mayeux R (2009) Validity of self-reported stroke in elderly African Americans, Caribbean Hispanics, and Whites. Arch Neurol 66, 834-840. [PubMed: 19433651]

[9]. Woodfield R, Group UKBSO, Follow-up UKB, Outcomes Working G, Sudlow CL (2015) Accuracy of Patient Self-Report of Stroke: A Systematic Review from the UK Biobank Stroke Outcomes Group. PLoS One 10, e0137538. [PubMed: 26355837]

[10]. Short ME, Goetzel RZ, Pei X, Tabrizi MJ, Ozminkowski RJ, Gibson TB, Dejoy DM, Wilson MG (2009) How accurate are self-reports? Analysis of self-reported health care utilization and absence when compared with administrative data. J Occup Environ Med 51, 786-796. [PubMed: 19528832]

[11]. Young J, Inouye SK (2007) Delirium in older people. BMJ 334, 842-846. [PubMed: 17446616]

[12]. Skinner TR, Scott IA, Martin JH (2016) Diagnostic errors in older patients: a systematic review of incidence and potential causes in seven prevalent diseases. Int J Gen Med 9, 137-146. [PubMed: 27284262]

[13]. Livingston G, Sommerlad A, Orgeta V, Costafreda SG, Huntley J, Ames D, Ballard C, Banerjee S, Burns A, Cohen-Mansfield J, Cooper C, Fox N, Gitlin LN, Howard R, Kales HC, Larson EB, Ritchie K, Rockwood K, Sampson EL, Samus Q, Schneider LS, Selbaek G, Teri L, Mukadam N (2017) Dementia prevention, intervention, and care. Lancet 390, 2673-2734. [PubMed: 28735855]

[14]. Kertesz A, Black SE, Nicholson L, Carr T (1987) The sensitivity and specificity of MRI in stroke. Neurology 37, 1580-1585. [PubMed: 3658160]

[15]. American Diabetes A (2019) 2. Classification and Diagnosis of Diabetes: Standards of Medical Care in Diabetes-2019. Diabetes Care 42, S13-S28. [PubMed: 30559228]

[16]. Folstein MF, Folstein SE, McHugh PR (1975) "Mini-mental state". A practical method for grading the cognitive state of patients for the clinician. J Psychiatr Res 12, 189-198. [PubMed: 1202204]

[17]. McKhann G, Drachman D, Folstein M, Katzman R, Price D, Stadlan EM (1984) Clinical diagnosis of Alzheimer's disease: report of the NINCDS-ADRDA Work Group under the auspices of Department of Health and Human Services Task Force on Alzheimer's Disease. Neurology 34, 939-944. [PubMed: 6610841]

[18]. Morris JC (1993) The Clinical Dementia Rating (CDR): current version and scoring rules. Neurology 43, 2412-2414.

[19]. Yesavage JA, Sheikh JI (1986) Geriatric Depression Scale (GDS). Clinical Gerontologist 5, 165173.

[20]. Price TR, Manolio TA, Kronmal RA, Kittner SJ, Yue NC, Robbins J, Anton-Culver H, O’Leary DH (1997) Silent brain infarction on magnetic resonance imaging and neurological abnormalities in community-dwelling older adults. The Cardiovascular Health Study. CHS Collaborative Research Group. Stroke 28, 1158-1164. [PubMed: 9183343]

[21]. Preventative Task Force US (2016) Screening for Abnormal Blood Glucose and Type 2 Diabetes Mellitus: Recommendation Statement. Am Fam Physician 93, Online.

[22]. National Academies of Sciences E, and Medicine (2015) Diagnostic Team Members and Tasks: Improving Patient Engagement and Health Care Professional Education and Training in Diagnosis In Improving Diagnosis in Health Care, Balogh EP, Miller BT, Ball JR, eds. The National Academies Press, Washington (DC).

[23]. Clayman ML, Roter D, Wissow LS, Bandeen-Roche K (2005) Autonomy-related behaviors of patient companions and their effect on decision-making activity in geriatric primary care visits. Soc Sci Med 60, 1583-1591. [PubMed: 15652689]

[24]. Cacchione PZ, Powlishta KK, Grant EA, Buckles VD, Morris JC (2003) Accuracy of collateral source reports in very mild to mild dementia of the Alzheimer type. J Am Geriatr Soc 51, 819 823. [PubMed: 12757569] 
[25]. Carr DB, Gray S, Baty J, Morris JC (2000) The value of informant versus individual's complaints of memory impairment in early dementia. Neurology 55, 1724-1726. [PubMed: 11113230]

[26]. Brunet HE, Miller JB, Shi J, Chung B, Munter BT, Sabbagh MN (2019) Does informant-based reporting of cognitive symptoms predict amyloid positivity on positron emission tomography? Alzheimers Dement (Amst) 11, 424-429. [PubMed: 31206008]

[27]. Kehoe R, Wu SY, Leske MC, Chylack LT, Jr. (1994) Comparing self-reported and physicianreported medical history. Am J Epidemiol 139, 813-818. [PubMed: 8178794]

[28]. Morgenstern LB, Lisabeth LD, Mecozzi AC, Smith MA, Longwell PJ, McFarling DA, Risser JM (2004) A population-based study of acute stroke and TIA diagnosis. Neurology 62, 895-900. [PubMed: 15037689]

[29]. Vernooij MW, Ikram MA, Tanghe HL, Vincent AJ, Hofman A, Krestin GP, Niessen WJ, Breteler MM, van der Lugt A (2007) Incidental findings on brain MRI in the general population. N Engl J Med 357, 1821-1828. [PubMed: 17978290]

[30]. Vermeer SE, Longstreth WT Jr., Koudstaal PJ (2007) Silent brain infarcts: a systematic review. Lancet Neurol 6, 611-619. [PubMed: 17582361]

[31]. Eze-Nliam C, Cain K, Bond K, Forlenza K, Jankowski R, Magyar-Russell G, Yenokyan G, Ziegelstein RC (2012) Discrepancies between the medical record and the reports of patients with acute coronary syndrome regarding important aspects of the medical history. BMC Health Serv Res 12, 78. [PubMed: 22448755]

[32]. Harlow SD, Linet MS (1989) Agreement between questionnaire data and medical records. The evidence for accuracy of recall. Am J Epidemiol 129, 233-248. [PubMed: 2643301]

[33]. Paganini-Hill A, Chao A (1993) Accuracy of recall of hip fracture, heart attack, and cancer: a comparison of postal survey data and medical records. Am J Epidemiol 138, 101-106. [PubMed: 8342528]

[34]. Smith EE, Saposnik G, Biessels GJ, Doubal FN, Fornage M, Gorelick PB, Greenberg SM, Higashida RT, Kasner SE, Seshadri S, American Heart Association Stroke C, Council on Cardiovascular R, Intervention, Council on Functional G, Translational B, Council on H (2017) Prevention of Stroke in Patients With Silent Cerebrovascular Disease: A Scientific Statement for Healthcare Professionals From the American Heart Association/American Stroke Association. Stroke 48, e44-e71. [PubMed: 27980126]

[35]. Skrobot OA, Black SE, Chen C, DeCarli C, Erkinjuntti T, Ford GA, Kalaria RN, O’Brien J, Pantoni L, Pasquier F, Roman GC, Wallin A, Sachdev P, Skoog I, group V, Ben-Shlomo Y, Passmore AP, Love S, Kehoe PG (2018) Progress toward standardized diagnosis of vascular cognitive impairment: Guidelines from the Vascular Impairment of Cognition Classification Consensus Study. Alzheimers Dement 14, 280-292. [PubMed: 29055812]

[36]. Skrobot OA, O'Brien J, Black S, Chen C, DeCarli C, Erkinjuntti T, Ford GA, Kalaria RN, Pantoni L, Pasquier F, Roman GC, Wallin A, Sachdev P, Skoog I, group V, Ben-Shlomo Y, Passmore AP, Love S, Kehoe PG (2017) The Vascular Impairment of Cognition Classification Consensus Study. Alzheimers Dement 13, 624-633. [PubMed: 27960092]

[37]. Day GS, Cruchaga C, Wingo T, Schindler SE, Coble D, Morris JC (2019) Association of Acquired and Heritable Factors With Intergenerational Differences in Age at Symptomatic Onset of Alzheimer Disease Between Offspring and Parents With Dementia. JAMA Netw Open 2, e1913491. [PubMed: 31617930]

[38]. Group SMIftSR, Williamson JD, Pajewski NM, Auchus AP, Bryan RN, Chelune G, Cheung AK, Cleveland ML, Coker LH, Crowe MG, Cushman WC, Cutler JA, Davatzikos C, Desiderio L, Erus G, Fine LJ, Gaussoin SA, Harris D, Hsieh MK, Johnson KC, Kimmel PL, Tamura MK, Launer LJ, Lerner AJ, Lewis CE, Martindale-Adams J, Moy CS, Nasrallah IM, Nichols LO, Oparil S, Ogrocki PK, Rahman M, Rapp SR, Reboussin DM, Rocco MV, Sachs BC, Sink KM, Still CH, Supiano MA, Snyder JK, Wadley VG, Walker J, Weiner DE, Whelton PK, Wilson VM, Woolard N, Wright JT Jr., Wright CB (2019) Effect of Intensive vs Standard Blood Pressure Control on Probable Dementia: A Randomized Clinical Trial. JAMA 321, 553-561. [PubMed: 30688979]

[39]. Ngandu T, Lehtisalo J, Solomon A, Levalahti E, Ahtiluoto S, Antikainen R, Backman L, Hanninen T, Jula A, Laatikainen T, Lindstrom J, Mangialasche F, Paajanen T, Pajala S, Peltonen M, Rauramaa R, Stigsdotter-Neely A, Strandberg T, Tuomilehto J, Soininen H, Kivipelto M 
(2015) A 2 year multidomain intervention of diet, exercise, cognitive training, and vascular risk monitoring versus control to prevent cognitive decline in at-risk elderly people (FINGER): a randomised controlled trial. Lancet 385, 2255-2263. [PubMed: 25771249]

[40]. Cowie CC, Rust KF, Byrd-Holt DD, Gregg EW, Ford ES, Geiss LS, Bainbridge KE, Fradkin JE (2010) Prevalence of diabetes and high risk for diabetes using A1C criteria in the U.S. population in 1988-2006. Diabetes Care 33, 562-568. [PubMed: 20067953]

[41]. Menke A, Casagrande S, Geiss L, Cowie CC (2015) Prevalence of and Trends in Diabetes Among Adults in the United States, 1988-2012. JAMA 314, 1021-1029. [PubMed: 26348752] 
Table 1.

Demographic and clinical characteristics of study participants.

\begin{tabular}{|c|c|c|}
\hline Characteristic & Stroke Cohort (n=862) & Diabetes Cohort $(n=1319)$ \\
\hline Age, mean $( \pm S D)$, years & $71.6(8.3)$ & $73.3(9.2)$ \\
\hline Female sex, n (\%) & $486(56.3)$ & $730(55.3)$ \\
\hline \multicolumn{3}{|l|}{ Race, n (\%) } \\
\hline Non-Hispanic White & $676(78.4)$ & $1083(82.1)$ \\
\hline African American & $179(20.8)$ & $219(16.6)$ \\
\hline Other & $7(0.8)$ & $17(1.3)$ \\
\hline Years of Education, mean $( \pm \mathrm{SD})$ & $15.9(2.6)$ & $15.8(2.7)$ \\
\hline MMSE Score, mean $( \pm \mathrm{SD})$ & $28.3(2.6)$ & $27.6(3.5)$ \\
\hline \multicolumn{3}{|l|}{ APOE 4 allele status, $\mathrm{n}(\%)$} \\
\hline Two copies (4/4) & $42(5.1)$ & $76(6.1)$ \\
\hline One copy (4/-) & $297(35.8)$ & $432(34.7)$ \\
\hline No copies (-/-) & $490(59.1)$ & $738(59.2)$ \\
\hline Missing & $33(3.8)$ & $73(5.5)$ \\
\hline \multicolumn{3}{|l|}{ Global CDR, n (\%) } \\
\hline 0 & $663(76.9)$ & $929(70.4)$ \\
\hline 0.5 & $142(16.5)$ & $243(18.4)$ \\
\hline 1.0 & $56(6.5)$ & $122(9.2)$ \\
\hline 2.0 & $1(0.1)$ & $25(1.9)$ \\
\hline
\end{tabular}

$\mathrm{APOE}=$ apolipoprotein CDR $=$ Clinical Dementia Rating; MMSE $=$ Mini-Mental State Examination, where a score of 30 is "best" and a score of 0 is "worst"; $\mathrm{SD}=$ standard deviation 
Table 2:

Association of participant-specific, cognitive function, medical history and other variables with concordance between reported stroke history and neuroimaging findings.

\begin{tabular}{|c|c|c|c|c|c|}
\hline & Variable & $\underset{(n=807)}{\text { Concordant }}$ & $\begin{array}{l}\text { Discordant } \\
(\mathbf{n}=\mathbf{5 5})\end{array}$ & $\begin{array}{c}\text { Measures of } \\
\text { Association } \\
\left(95 \%_{\mathrm{CI}}\right)^{\dagger}\end{array}$ & p value \\
\hline \multirow{7}{*}{ Participant-Specific Factors } & Age, mean $( \pm$ SD $)$, years & $71.3(8.3)$ & $75.7(7.7)$ & $-4.4(-6.7,-2.1)$ & $<0.001$ \\
\hline & Female, n (\%) & $452(56)$ & $34(61.8)$ & $0.8(0.5,1.4)$ & 0.40 \\
\hline & Race, n (\%) & & & & \\
\hline & Non-Hispanic White & $635(78.7)$ & $41(74.5)$ & $1.3(0.7,2.4)$ & 0.47 \\
\hline & African American & $165(20.4)$ & $14(25.5)$ & $0.8(0.4,1.4)$ & 0.38 \\
\hline & Years of Education, mean $( \pm \mathrm{SD})$ & $15.9(2.6)$ & $16.0(2.7)$ & $-0.06(-0.8,0.7)$ & 0.87 \\
\hline & $A P O E \varepsilon 4$ carrier $(4 / 4$ or $4 /-)$ & $317(40.9)$ & $22(40.7)$ & $0.99(0.6,1.7)$ & 0.98 \\
\hline \multirow{2}{*}{ Cognitive Function } & MMSE, mean $( \pm$ SD) & $28.3(2.5)$ & $27.3(3.3)$ & $1.0(0.3,1.7)$ & 0.005 \\
\hline & Cognitive impairment, n (\%) & $181(22.4)$ & $18(32.7)$ & $0.6(0.3,1.1)$ & 0.08 \\
\hline \multirow{4}{*}{ Medical History } & Hypertension, n (\%) & $417(51.8)$ & $38(69.1)$ & $0.5(0.3,0.9)$ & 0.01 \\
\hline & Heart Disease, n (\%) & $225(27.9)$ & $19(34.5)$ & $0.7(0.4,1.3)$ & 0.29 \\
\hline & Depression, n (\%) & $94(11.7)$ & $8(14.8)$ & $0.7(0.4,1.7)$ & 0.49 \\
\hline & Tobacco Use, n (\%) & $378(47)$ & $24(43.6)$ & $1.2(0.7,2.0)$ & 0.63 \\
\hline \multirow{3}{*}{ Other } & Family Member CS ${ }^{*}, \mathbf{n}(\%)$ & $661(81.9)$ & $39(70.9)$ & $1.9(1.0,3.4)$ & 0.04 \\
\hline & $\begin{array}{l}\text { Delay from assessment to imaging, mean days } \\
\text { (SD) }\end{array}$ & $106.5(79.5)$ & $112.9(80.3)$ & $-6.3(-28.1,15.4)$ & 0.57 \\
\hline & Small infarct, n (\%) & $5(0.6)$ & $33(60.0)$ & $0.004(0.001,0.012)$ & $<0.001$ \\
\hline
\end{tabular}

${ }^{\dagger}$ Measures of association are reported as the difference between means $(95 \% \mathrm{CI}$ ) for continuous variables and odd ratios (univariate logistic regression, $95 \% \mathrm{CI}$ ) for categorical variables

* Participant's Collateral Source (CS) was a first-degree relative (spouse, adult child or sibling)

$\mathrm{p}<0.1=$ bolded

$\mathrm{APOE}=$ apolipoprotein E; MMSE $=$ Mini-Mental State Examination[16]; SD = standard deviation 
Table 3:

Association of participant-specific, cognitive function, medical history and other variables with concordance between reported diabetes history and $\mathrm{HbA1c}$.

\begin{tabular}{|c|c|c|c|c|c|}
\hline & Variable & $\underset{(n=1247)}{\text { Concordant }}$ & $\begin{array}{l}\text { Discordant } \\
(n=72)\end{array}$ & $\begin{array}{c}\text { Measures of } \\
\text { Association } \\
\left(95 \%_{\mathrm{CI}}\right)^{\dagger}\end{array}$ & p value \\
\hline \multirow{7}{*}{ Participant-Specific Factors } & Age, mean $( \pm$ SD $)$, years & $73.2(9.2)$ & $75.1(8.2)$ & $-2.0(-4.2,0.2)$ & 0.08 \\
\hline & Female, n (\%) & $693(55.6)$ & $37(51.4)$ & $1.2(0.7,1.9)$ & 0.49 \\
\hline & Race, $n(\%)$ & & & & \\
\hline & Non-Hispanic White & 1035 (83.0) & $48(66.7)$ & $2.4(1.5,4.1)$ & 0.001 \\
\hline & African American & $197(15.8)$ & $22(30.6)$ & $0.4(0.3,0.7)$ & 0.001 \\
\hline & Years of Education, mean $( \pm \mathrm{SD})^{t}$ & $15.8(2.6)$ & $15.7(3.1)$ & $0.1(-0.5,0.7)$ & 0.79 \\
\hline & $A P O E \varepsilon 4$ carrier (4/4 or $4 /-)$ & $479(40.6)$ & $29(43.3)$ & $0.9(0.5,1.5)$ & 0.67 \\
\hline \multirow{2}{*}{ Cognitive Function } & MMSE, mean $( \pm \mathrm{SD})$ & $27.6(3.5)$ & $27.1(3.9)$ & $0.4(-0.3,1.3)$ & 0.23 \\
\hline & Cognitive impairment, $\mathrm{n}(\%)$ & $367(29.4)$ & $23(31.9)$ & $0.9(0.5,1.5)$ & 0.65 \\
\hline \multirow{4}{*}{ Medical History } & Hypertension, n (\%) & $658(52.8)$ & $56(77.8)$ & $0.3(0.2,0.6)$ & $<0.001$ \\
\hline & Heart Disease, n (\%) & $312(25.0)$ & $24(33.3)$ & $0.7(0.4,1.1)$ & 0.12 \\
\hline & Depression, $\mathrm{n}(\%)$ & $180(14.4)$ & $8(11.1)$ & $1.4(0.6,2.9)$ & 0.43 \\
\hline & Tobacco Use, n (\%) & $579(46.5)$ & $40(55.6)$ & $0.7(0.4,1.1)$ & 0.14 \\
\hline \multirow{4}{*}{ Other } & Family Member CS ${ }^{*}, \mathrm{n}(\%)$ & $1021(82.0)$ & $56(77.8)$ & $1.3(0.7,2.3)$ & 0.37 \\
\hline & $\begin{array}{l}\text { Delay from assessment to imaging, mean days } \\
\text { (SD) }\end{array}$ & $16.8(63.5)$ & $19.1(52.0)$ & $-2.3(-17.2,12.7)$ & 0.77 \\
\hline & HgA1c, mean $( \pm$ SD $)$ & $5.7(0.7)$ & $6.4(0.7)$ & $-0.6(-0.78,-0.45)$ & $<0.001$ \\
\hline & $\begin{array}{l}\text { Impaired glucose tolerance }(\mathrm{HgA1c}=6.0- \\
6.4), \mathrm{n}(\%)\end{array}$ & $173(13.9)$ & $24(33.3)$ & $0.3(0.2,0.5)$ & $<0.001$ \\
\hline
\end{tabular}

${ }^{\dagger}$ Measures of association are reported as the difference between means $(95 \% \mathrm{CI}$ ) for continuous variables and odd ratios (univariate logistic regression, $95 \% \mathrm{CI}$ ) for categorical variables

tData missing for one participant $(\mathrm{n}=1246)$

*

* Participant's Collateral Source (CS) was a first-degree relative (spouse, adult child or sibling)

$\mathrm{p}<0.1=$ bolded

$\mathrm{APOE}=$ apolipoprotein $\mathrm{E} ; \mathrm{MMSE}=$ Mini-Mental State Examination[16] $\mathrm{SD}=$ standard deviation 
Table 4:

Association of participant-specific, cognitive function, medical history and other variables with false positive and false negative reporting.

\begin{tabular}{|c|c|c|c|c|c|c|c|}
\hline & \multirow[b]{2}{*}{ Variable } & \multicolumn{3}{|c|}{ Stroke/Infarct } & \multicolumn{3}{|c|}{ Diabetes } \\
\hline & & $\begin{array}{c}\text { False } \\
\text { Positive } \\
(\mathbf{n}=17)\end{array}$ & $\begin{array}{c}\text { False } \\
\text { Negative } \\
(\mathbf{n}=\mathbf{3 8})\end{array}$ & p value & $\begin{array}{c}\text { False } \\
\text { Positive } \\
(\mathrm{n}=43)\end{array}$ & $\begin{array}{c}\text { False } \\
\text { Negative } \\
(\mathbf{n}=29)\end{array}$ & p value \\
\hline \multirow{7}{*}{$\begin{array}{l}\text { Participant-Specific } \\
\text { Factors }\end{array}$} & Age, mean $( \pm \mathrm{SD})$, years & $75.7(6.2)$ & $75.8(8.3)$ & 0.96 & $75.5(7.3)$ & $74.6(9.5)$ & 0.65 \\
\hline & Female, n (\%) & $14(82.4)$ & $20(52.6)$ & 0.04 & $22(51.2)$ & $15(51.7)$ & 0.96 \\
\hline & Race, n (\%) & & & & & & \\
\hline & Non-Hispanic White & $10(58.8)$ & $31(81.6)$ & 0.07 & $29(67.4)$ & $19(65.5)$ & 0.87 \\
\hline & African American & $7(41.2)$ & $7(18.4)$ & .07 & $13(30.2)$ & $9(31.0)$ & 0.94 \\
\hline & Years of Education, mean $( \pm \mathrm{SD})$ & $15.9(2.4)$ & $16.0(2.8)$ & 0.88 & $15.5(3.0)$ & $16.0(3.2)$ & 0.47 \\
\hline & $A P O E \varepsilon 4$ carrier (4/4 or $4 /-)$ & $5(29.4)$ & $17(45.9)$ & 0.25 & $15(38.5)$ & $14(50.0)$ & 0.35 \\
\hline \multirow{2}{*}{ Cognitive Function } & MMSE, mean $( \pm S D)$ & $27.4(3.8)$ & $27.3(3.1)$ & 0.95 & $27.1(4.0)$ & $27.2(3.8)$ & 0.95 \\
\hline & Cognitive impairment, $\mathrm{n}(\%)$ & $7(41.2)$ & $11(28.9)$ & 0.37 & $11(25.6)$ & $12(41.4)$ & 0.16 \\
\hline \multirow{4}{*}{ Medical History } & Hypertension, n (\%) & $12(70.6)$ & $26(68.4)$ & 0.87 & $8(18.6)$ & $8(27.6)$ & 0.37 \\
\hline & Heart Disease, n (\%) & $6(35.3)$ & $13(34.2)$ & 0.94 & $14(32.6)$ & $10(34.5)$ & 0.87 \\
\hline & Depression, $\mathrm{n}(\%)$ & $4(23.5)$ & $4(10.8)$ & 0.24 & $6(14.0)$ & $2(6.9)$ & 0.35 \\
\hline & Tobacco Use, n (\%) & $9(52.9)$ & $15(39.5)$ & 0.39 & $24(55.8)$ & $16(55.2)$ & 0.96 \\
\hline \multirow[b]{2}{*}{ Other } & Family Member CS ${ }^{*}, \mathrm{n}(\%)$ & $11(64.7)$ & $28(73.7)$ & 0.50 & $33(76.7)$ & $23(79.3)$ & 0.80 \\
\hline & $\begin{array}{l}\text { Delay from assessment to imaging } \\
\text { or HbA1c, mean days (SD) }\end{array}$ & $90.3(63.8)$ & $123.0(85.6)$ & 0.17 & $22.4(59.9)$ & $14.0(37.7)$ & 0.51 \\
\hline
\end{tabular}

$\mathrm{APOE}=$ apolipoprotein E $; \mathrm{CDR}=$ Clinical Dementia Rating $;$ MMSE $=$ Mini-Mental Status Examination; SD = standard deviation * Participant's Collateral Source (CS) was a first-degree relative (spouse, adult child or sibling) $\mathrm{p}<0.05=$ bolded 
Table 5:

Unconscious and conscious factors that may contribute to discordant reporting of medical history, and potential mitigating strategies.

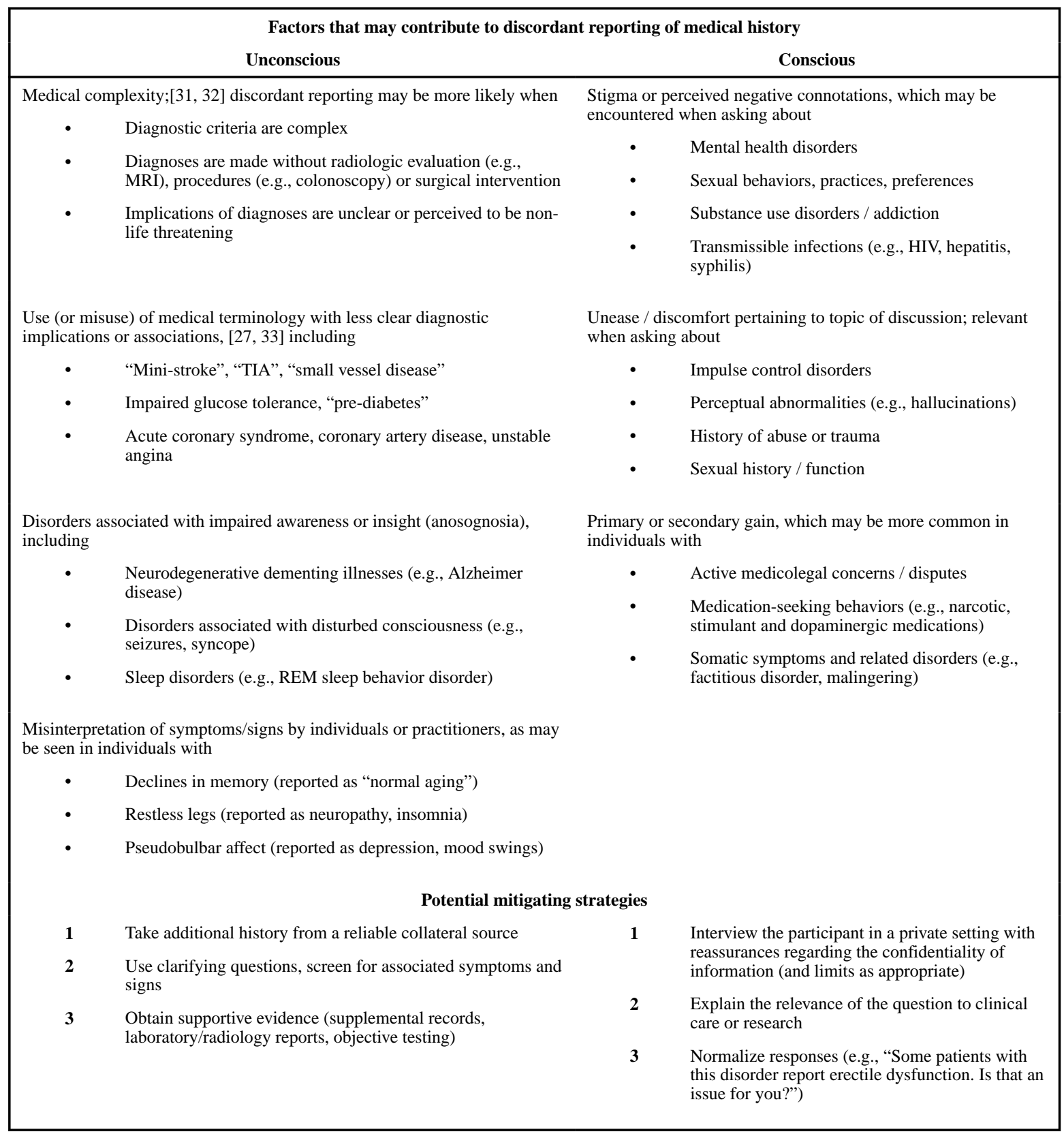

HIV = human immunodeficiency virus; REM = rapid eye movement; TIA = transient ischemic attack 